\title{
E o casamento acabou: uma análise do arquivo de Veja sobre o imaginário da mulher divorciada
}

\author{
Silmara Dela Silva ${ }^{1}$ \\ Fernanda Luzia Lunkes ${ }^{2}$
}

\begin{abstract}
Resumen: Este artículo trata de comprender algunos de los movimientos de constitución de los sentidos en el archivo de la revista "Veja" sobre la mujer divorciada en dos momentos distintos: en el final de la década de 1970 y en la actualidad. Empezamos con algunas reflexiones sobre el concepto de archivo en el cuadro teórico y metodológico del Análisis del discurso. En un segundo momento, movilizando la noción teórica del trayecto temático, analisamos discursivamente un reportaje de 1979 de "Veja” y la retomada hecha por la própia revista en la misma matéria, en su edición conmemorativa de sus 45 años, que circuló en septiembre de 2013; se centra en los procesos de producción de sentidos, sobre todo en lo que se refiere a la imagen que en ellas se constituyen para la mujer divorciada. Nuestro analisis señala el modo cómo, al constituir una memória de archivo sobre la mujer divorciada, "Veja" inscribe su decir en lo ya dicho, actualizando los sentidos sobre la fragilidad femenina, comunes en nuestra formación social.
\end{abstract}

Palabras-clave: Análisis del discurso; archivo; formación imaginária; mujer.

Resumo: Este trabalho busca compreender alguns dos movimentos de constituição de sentidos no arquivo da revista Veja sobre a mulher divorciada em dois momentos distintos: no final da década de 1970 e na atualidade. Iniciamos com algumas reflexões sobre o conceito de arquivo no quadro teórico-metodológico da análise de discurso. Em um segundo momento, mobilizando a noção teórica de trajeto temático, analisamos discursivamente uma reportagem de 1979 de Veja e a retomada feita pela própria revista desta mesma matéria, na edição comemorativa aos seus 45 anos, que circulou em setembro de 2013, com foco nos processos de produção de sentidos principalmente no que se refere à imagem que nelas se constituem para a mulher divorciada. Nossas análises apontam o modo como, ao constituir uma memória de arquivo sobre a mulher divorciada, Veja inscreve o seu dizer no já-dito, atualizando sentidos sobre a fragilidade feminina, correntes em nossa formação social.

Palavras-chave: Análise de discurso; arquivo; formação imaginária; mulher.

1 Doutora em Linguística pela UNICAMP. Professora Adjunta do Departamento de Ciências da Linguagem, Instituto de Letras da UFF.

2 Doutora em Estudos da Linguagem pela UFF. Tutora nas disciplinas de Linguística I e III no curso de Letras da UFF (modalidade a distância). 


\begin{abstract}
"Todo arquivo [...] é identificado pela presença de uma data, de um nome próprio, de uma chancela institucional etc., ou ainda pelo lugar que ele ocupa em uma série. Essa identificação, puramente institucional, é para nós insuficiente: ela diz pouco do funcionamento do arquivo." Guilhamou e Maldidier (2010, p. 162)
\end{abstract}

As reflexões acerca da noção de arquivo e as leituras suscitadas pelo gesto de arquivar têm se mostrado bastante produtivas no campo teórico da análise de discurso no Brasil. Motivadas pelo debate trazido por Michel Pêcheux ainda no início da década de 1980, em seu texto "Ler o arquivo hoje" ([1981] 2010), tais reflexões têm se organizado em torno de dois principais eixos: os gestos de constituição de arquivos em diferentes instâncias; e as análises das discursividades suscitadas por esse gesto, sem perder de vista as implicações da prática do arquivamento para o modo como se constituem os sentidos nas materialidades arquivadas.

O interesse pelo arquivo e o seu funcionamento decorre, justamente, da proposta que constitui a própria análise de discurso como disciplina na França, na década de 1960: a atenção às práticas de leitura e interpretação e, mais especificamente, o "reconhecimento de que a leitura deve se sustentar em um dispositivo teórico", de modo a promover a sua "des-naturalização", como afirma Orlandi (2006, p. 13).

Neste artigo, temos como um dos objetivos a análise da discursividade em que se inscreve o dizer de Veja, uma das principais revistas em circulação no país, acerca da mulher divorciada. Para tanto, constituímos o nosso corpus a partir de duas reportagens que circularam na revista em dois momentos distintos: a primeira, no ano de 1979, quando a publicação dedicou a sua capa a um seriado de TV que tinha como protagonista uma mulher "descasada"; e a segunda, no ano de 2013, quando essa primeira reportagem dedicada à questão da mulher e do divórcio é retomada em uma das matérias que compõem em seu conjunto a edição comemorativa aos 45 anos de Veja. Norteamos a nossa análise pelo imaginário que a revista Veja constitui para a mulher divorciada, buscando compreender os modos como tais sentidos se constituem nessa publicação integrante da chamada imprensa de referência (MARIANI, 1998) no Brasil, nesses dois diferentes momentos históricos considerados.

Como um segundo objetivo de nossa análise, mas igualmente importante, direcionamos o nosso olhar para o gesto de constituição de arquivo empreendido pela revista, uma vez que $V e j a$, em sua edição comemorativa de setembro de 2013, propõe-se a revisitar os seus 45 anos de circulação no país, promovendo, desse modo, um gesto de leitura de seu histórico de publicações, e consequentemente, de seu arquivo. Interessa-nos, desse modo, o arquivo de Veja que tematiza a mulher divorciada, considerando a sua historicidade, pois, conforme afirmam Guilhamou e Maldidier (2010, p. 162), no excerto que trouxemos como epígrafe para este artigo, o simples fato de nos debruçarmos sobre um arquivo institucional, que é o caso do arquivo de Veja, nos "diz pouco" sobre o seu "funcionamento". Compreender a historicidade, ou seja, aquilo que na "[...] linguagem organiza sentidos para as relações de poder presentes em uma formação social, produção esta sempre afetada pela memória do dizer e sempre sujeita à possibilidade de rupturas no dizer" (MARIANI, 1998, p. 24), permite situarmos alguns dos movimentos discursivos de Veja no funcionamento de (re)leituras do arquivo e que, ao mesmo tempo, atua como um outro gesto de constituição de arquivo. 
Começamos esta nossa reflexão revisitando brevemente a noção de arquivo no quadro teórico da análise de discurso. Em Pêcheux ([1981] 2010, p. 51), temos que o arquivo pode ser entendido, "em sentido amplo", conforme afirma o autor, como um "campo de documentos pertinentes e disponíveis sobre uma questão.”.

Pensar o arquivo como um conjunto de documentos é prática corrente em áreas que trabalham diretamente com a gestão arquivística, como a ciência da informação, por exemplo. Em seu percurso sobre os modos de se pensar a teoria do arquivo na ciência da informação, de modo que pudesse estabelecer um contraponto em relação ao arquivo discursivo, Romão (2011) nos mostra que normalmente o arquivo, dessa perspectiva teórica, "funciona como montagem de memória, como bricolagem de diferentes materialidades para compor uma construção de dados pertinentes a um órgão" (idem, p. 99). Desse modo, ainda nos termos da autora, "o arquivo restitui um todo que imaginariamente sustenta o efeito de inteireza", sendo entendido como composto por um grupo de documentos que "passam a estar atados e/ou sustentados na/pela ligação de um alinhamento que se supõe óbvio pelo efeito ideológico de evidência" (ibidem).

Distanciando-se dessa posição, e problematizando-a, Pêcheux ([1981] 2010), em suas considerações acerca das questões que concernem à leitura de arquivo, já ressaltava a importância de se considerar "as evidências práticas que organizam essas leituras" (p. 51) decorrentes do arquivo, de modo a questionar o próprio trabalho de sua constituição. Ou seja, as regras que definem quais documentos são "pertinentes" e deverão estar "disponíveis" em um arquivo determinam leituras possíveis e isso não pode ser desconsiderado em uma análise. Dessa perspectiva, o arquivo na análise de discurso não é tomado como um dado, uma evidência naturalizada no gesto de arquivamento. Todo arquivo implica processos de seleção e exclusão, em decorrência do que se organizam evidências de leitura, como nos diz Pêcheux (idem).

Ao retomar a afirmação de Pêcheux (idem, ibidem), do arquivo como "campo de documentos", que mencionamos anteriormente, Romão (2011) irá explicar que o arquivo discursivo não se refere a um "grupo de documentos físicos a serem guardados, mas a um campo discursivo de documentos ligados a zonas da memória do dizer" (ROMÃO, 2011, p. 105), o que aponta para a compreensão do arquivo em Pêcheux como discursividade. Por consequência, o trabalho de leitura de arquivo, conforme Pêcheux, deve se dar na "relação entre língua como sistema sintático intrinsecamente passível de jogo, e a discursividade como inscrição de efeitos linguísticos materiais na história" ([1981] 2010, p. 58).

Quando pensado discursivamente, o arquivo comporta mais que um simples conjunto de documentos agrupados por uma lógica institucional. Ele direciona e interdita efeitos de sentidos, que se produzem pela inscrição da língua na história; e enquanto discurso, a sua leitura, por consequência, não pode prescindir de suas condições de produção (PÊCHEUX, [1969] 1997). "Entre a materialidade da língua e da história aí se situa para Pêcheux o arquivo.” (ROMÃO; LEANDRO-FERREIRA; DELA-SILVA, 2011, p. 13).

O arquivo estabelece, assim, uma estreita relação com a noção de memória discursiva, entendida como o já-dito que constitui o dizer. Essa relação é trabalhada por Orlandi (2006) a partir da distinção entre memória discursiva e memória de arquivo. Conforme Orlandi, diferentemente da memória discursiva, que consiste no "conjunto de enunciações já ditas e esquecidas e que são irrepresentáveis" (2006, p. 22), mas que constitui o discurso, a memória de arquivo "representa o discurso documental, a memória institucionalizada que é aquela que fica disponível, arquivada em nossas instituições e da qual não esquecemos" 
(ibidem), justamente porque o arquivo está ali apontando o que deve ser lembrado e, por extensão, o que não pode ser esquecido. Em trabalho anterior, Orlandi (2002, p. 11) já havia afirmado que "Essa memória [de arquivo] tem relações complexas com o saber discursivo, ou seja, com o interdiscurso, que é a memória irrepresentável, que se constitui ao longo de toda uma história de experiência de linguagem.”.

Apesar de se relacionar com a memória discursiva, a memória de arquivo não se sobrepõe a ela. A memória de arquivo se constitui em função de um gesto de arquivamento, da institucionalização de um arquivo; gesto este que estabelece os seus limites, as suas bordas, apesar do desejo de completude que o constitui. Entendemos que o arquivo envolve, então, "tanto as materialidades sob investigação, como um modo de observar o seu funcionamento e mudança no seio de uma sociedade" (ROMÃO; LEANDRO-FERREIRA; DELA-SILVA, 2011, p. 13) e, em seu funcionamento, permite a constituição de uma memória de arquivo. Por sua vez, a memória de arquivo, "a despeito de ser administrada por uma instituição, é também um discurso e, desse modo, está sujeita ao funcionamento da memória discursiva" (DELA-SILVA, no prelo). Em consequência, analisar o arquivo discursivamente, como já afirmamos, requer considerar as suas condições de produção, a sua historicidade. Conforme Nunes (2008, p. 82): "Ler os documentos de arquivo conduz a explicitar os gestos de interpretação que subjazem a sua elaboração, evitando-se reproduzir uma história já dada, fixada, e mostrando seu processo de construção.”.

É desta perspectiva que nos voltamos ao arquivo da revista Veja. O primeiro ponto que julgamos relevante considerar é que o trabalho com a construção de uma memória de arquivo é uma prática corrente nessa publicação. Uma prova disso é que, ao completar 40 anos de circulação, a revista passou a disponibilizar o seu acervo digital, constituído pela íntegra das edições que circularam em suas publicações semanais, desde 1968. Pensando discursivamente a respeito desse acervo e do gesto de constituição de arquivos que ele representa, as autoras Romão, Leandro-Ferreira e Dela-Silva (2011) afirmam que:

De fato, o acervo possibilita compreender o olhar da revista para o cotidiano e os saberes que ela elegeu como acontecimento jornalístico no período mencionado, com base em seu perfil editorial, na imagem que constitui para os seus leitores e para si. Contudo, também permite a reflexão sobre o que ficou de fora deste "grande arquivo", sobretudo aquilo que "escapou" ao olhar da revista, aquilo que foi preterido pelos sujeitos jornalistas ou mesmo silenciado em cada edição. (2011, p. 13-14).

Desse modo, entendemos que o acervo digital de Veja, como todo arquivo, é não-todo, e a despeito do slogan adotado pela publicação quando da publicação de seu acervo digital - "Os fatos mais importantes do país e do mundo nas páginas de Veja" -, ele nos apresenta um recorte de acontecimentos alçados à condição de acontecimentos jornalísticos pela revista (DELA-SILVA, 2008), a partir de sua posição ideológica de imprensa de referência (MARIANI, 1998). Por isso, ao olharmos para o acervo digital da revista Veja como um arquivo discursivo, o que buscamos são as discursividades que ali se constituem, e que deixam as suas marcas na materialidade da língua. Isso porque, conforme nos advertem Guilhamou e Maldidier:

...o arquivo não é o reflexo passivo de uma realidade institucional, ele é, dentro de sua materialidade e diversidade, ordenado por sua abrangência social. $\mathrm{O}$ arquivo não é um simples documento no qual se encontram referências; ele permite uma leitura que traz à tona dispositivos e configurações significantes. (2010, p. 162). 
$\mathrm{O}$ arquivo que constitui Veja com o seu acervo virtual passa, assim, pelos movimentos dos gestos de leitura que ele suscita e, igualmente, pelos efeitos de sentidos que ali não se inscrevem, sendo silenciados (ORLANDI, 2002a).

Um novo gesto de constituição de arquivo empreendido pela revista é aquele que constitui a edição comemorativa aos seus 45 anos de circulação, e que aqui nos interessa mais particularmente. A edição especial, que circulou em setembro de 2013, tem como proposta apresentar 45 matérias jornalísticas que, nos termos expressos na capa da publicação, revisitam "45 reportagens que fizeram - e fazem - história" (VEJA, 2013). Sem adentrarmos na discussão acerca da relação entre a prática jornalística e o "fazer história", que escapa à proposta deste artigo ${ }^{3}$, interessa-nos esse movimento empreendido pela revista de retornar às suas publicações, dispostas em seu acervo digital, e dentre elas recortar 45 temas que foram abordados em textos assinados por especialistas em cada uma das temáticas contempladas na edição comemorativa. Trata-se, a nosso ver, de um gesto de leitura de arquivo que a revista faz de si, que permite dizer aos seus leitores aquilo que precisa ser lembrado do "todo" que imaginariamente circulou em suas páginas, em 45 anos de publicação, constituindo uma memória de arquivo.

Dentre todas as matérias retomadas pela edição comemorativa, organizadas pela revista em sete editorias - Imprensa, Brasil, Internacional, Economia, Geral, Cultura e Antologia -, elegemos para nossa análise o texto que tem como título "Malu Mulher de verdade", assinado pela historiadora Mary Del Priori, e que tem como propósito retomar a matéria especial intitulada "A viajante solitária", publicada na edição de 18 de julho de 1979, capa de Veja naquela ocasião, com a chamada "A mulher descasada". Propomos, assim, analisar o imaginário de mulher divorciada constituído na publicação nesses dois momentos históricos e, a partir disso, refletir acerca dos efeitos de sentidos do gesto de leitura de arquivo empreendido por Veja nessa retomada.

Para norteamos a constituição de nosso corpus de análise a partir de uma temática depreendida do arquivo de Veja - no caso, a mulher divorciada -, recorremos à noção de percurso temático, conforme trabalhada por Guilhaumou e Maldidier (2010), bem como por Nunes (1994). De modo a se distanciar de um ponto de vista referencialista a respeito da noção de tema, Guilhaumou e Maldidier propõem pensar uma temática como "a distinção entre 'o horizonte de expectativas' - o conjunto de possibilidades atestadas em uma situação histórica dada - e o acontecimento discursivo que realiza uma dessas possibilidades" (2010, p. 164), entendendo o acontecimento discursivo como aquele que pode ser "apreendido na consistência de enunciados que se entrecruzam em um momento dado" (ibidem).

Dessa perspectiva, ao optarmos por tratar da temática mulher divorciada no arquivo de Veja, não pressupomos a existência de um referencial fixo acerca do qual discorrem as matérias jornalísticas em questão, mas temos como foco os efeitos de sentidos produzidos a esse respeito nesses dois momentos históricos supracitados. Segundo Nunes (1994, p. 115), "ao falarmos em tema, não pressupomos que haja um referencial fixo (seja discursivo ou real) sobre o qual o discurso se detém. É preciso levar em conta as condições de produção em que ele se insere". A partir dessa concepção, a nossa temática - mulher divorciada - é aqui considerada como uma "série discursiva" que se marca nos textos que constituem o nosso corpus de análise, “construindo espaços de identificação, transformação, contradição etc.” (NUNES, 1994, p. 115).

3 Esta relação foi abordada por Dela Silva em apresentação oral intitulada "Fazer jornalismo, fazer história? Os 45 anos de Veja, o discurso jornalístico, o (im)perceptível", na mesa-redonda "O imperceptível", durante a Jornada "O indizível, o ininteligível e o imperceptível: o sujeito contemporâneo e seus arquivos", realizada pelo Laboratório Arquivos do Sujeito (LAS), na UFF, em dezembro de 2013. 
Em nosso percurso analítico, nas identificações, transformações, contradições (NUNES, 1994) e outros efeitos de sentidos produzidos sobre a mulher divorciada, estão em jogo as imagens que são construídas sobre a mulher nesta condição.

Pêcheux ([1969] 1997, p. 82) explica que o discurso não pode ser compreendido enquanto uma "informação entre A e B", mas como efeitos de sentidos que são produzidos entre tais lugares sociais. Opacificando o esquema de comunicação formulado por Jakobson ([1960] 2010), Pêcheux propõe a noção de formações imaginárias, e explica que elas:

[...] designam o lugar que A e B se atribuem cada um a si e ao outro, a imagem que se fazem de seu próprio lugar e do lugar do outro. Se assim ocorre, existem nos mecanismos de qualquer formação social regras de projeção, que estabelecem as relações entre as situações (objetivamente definíveis) e as posições (representações dessas situações). (PÊCHEUX, [1969] 1997, p. 82).

Deste modo, Pêcheux (idem) estabelece "regras de projeção" nas relações entre A e $\mathrm{B}$, que não são individuais e que estão presentes em todo processo discursivo. Trazendo nosso objetivo na análise e abordando a síntese que Pêcheux faz sobre o funcionamento das formações imaginárias, situemos aquela projeção que nos interessa neste percurso. Trata-se daquela que Pêcheux explica como sendo "o ponto de vista de A sobre R", ou seja, sobre o referente do discurso, e que funciona implicitamente por meio da seguinte pergunta: "De que lhe falo assim?" (idem, p. 84). Tal formação imaginária é sintetizada por Pêcheux por meio da fórmula "IA(R)". Em nosso caso, estamos considerando enquanto referente a mulher divorciada e, quando e se for o caso, outras imagens em jogo no discurso de Veja. Conforme depreenderemos em nossas análises, as imagens produzidas sobre televisão também interessam, à medida que apontam para os efeitos de sentidos sobre o telespectador e sobre os sentidos por ele produzidos em uma dada formação social em relação à mulher divorciada.

Comecemos analisando as imagens em jogo na matéria de 1979, que aborda, conforme mencionamos anteriormente, um seriado de TV (Malu Mulher), cuja protagonista era uma mulher divorciada, interpretada pela atriz Regina Duarte ${ }^{4}$. Na reportagem de capa que circula na revista cerca de dois meses após a estreia do seriado na televisão, e que constitui o nosso corpus, o discurso de Veja aproxima a personagem Malu da atriz que a interpreta, destacando o fato de Regina Duarte também ser uma mulher divorciada, como veremos mais adiante.

Dada a relevância da capa em uma publicação jornalística, iniciamos nosso gesto de análise a partir dessa materialidade. A capa dessa edição de Veja apresenta a fotografia em close da atriz Regina Duarte, com expressão séria e olhar que encara o leitor, acompanhada da legenda: "Regina Duarte, em "Malu Mulher"”; e da chamada em destaque: "A mulher descasada". É sobre esse modo de designar a mulher divorciada na capa de Veja que nos detemos: "descasada", uma primeira qualificação constitutiva dos efeitos de sentidos sobre a mulher nesta sua nova condição na sociedade brasileira à época. A manchete na capa de

4 Com um total de 76 episódios, exibidos semanalmente na Rede Globo de Televisão de 24 de maio de 1979 a 22 de dezembro de 1980, o seriado tinha como proposta "compor um retrato da condição da mulher brasileira, mostrando as dificuldades que ela enfrenta no cotidiano" (DICIONÁRIO DA TV GLOBO, 2003, p. 386). No enredo, o destaque é dado à protagonista Malu, que decide terminar o casamento de 13 anos, após descobrir as traições do marido. Em cada episódio são retratadas situações vividas por Malu durante e após o fim de seu casamento, como o processo de separação, os problemas financeiros, a busca por emprego e a sua vida afetiva. 
Veja retoma o título em português do filme de Paul Mazurkis, "Uma mulher descasada", que, conforme registros no Dicionário da TV Globo (2003, p. 386) e na reportagem da revista, teria sido a inspiração para o seriado.

Como afirma Orlandi (2001), os sentidos têm uma história e o dizer está sempre em relação a outros dizeres, e isso certamente se aplica à versão em português feita para o título do filme de Paul Mazurkis, que são os termos selecionados por Veja para a sua manchete de capa. Em relação ao título do filme, o discurso da revista promove um deslocamento de sentidos ao substituir o artigo "uma" por "a" (em: "a" mulher descasada), o que promove um efeito de generalização sobre o quem se fala. Enquanto no filme conta-se a história de "uma mulher", a capa de Veja, ainda que retome a história vivida nas telas por Regina Duarte, como destaca a legenda que acompanha a foto da atriz, faz incidir o seu dizer sobre "a" "mulher descasada", entendida como uma categoria nova em nossa formação social à época.

A princípio, podemos inscrever a expressão "mulher descasada" em uma rede parafrástica (ORLANDI, 2001) da qual fazem parte também expressões como "mulher separada" e "mulher divorciada", por exemplo. Contudo, não é nenhuma dessas expressões que comparecem na materialidade significante da capa de Veja, e sim "mulher descasada". Em "descasada", o prefixo "des" marca um direcionamento de sentidos ao apontar para aquilo que está ausente, aquilo que falta ao sujeito e que, por isso, deve ser por ele buscado. Este movimento discursivo do prefixo "des" a expressar sentidos de falta é observado em gramáticas e dicionários, como no Dicionário Houaiss da Língua Portuguesa (2009), que registra três acepções para esse prefixo, sendo as duas primeiras associadas a uma rede de sentidos que direcionam o dizer para a falta e a ausência de algo .

Como entendemos, com Pêcheux ([1975] 1997a, p. 160), que as palavras, expressões, proposições ganham seus sentidos no "processo sócio-histórico" no qual "são produzidas", determinadas pelas "posições ideológicas que estão em jogo" nesse processo, assumimos que é nesta rede discursiva de "oposição, negação ou falta" que se inscreve o termo "descasada", em seu funcionamento para qualificar o dizer de Veja sobre a mulher. Trata-se de uma categoria de mulher a quem falta o casamento, uma falta que precisa ser justificada, como podemos observar, por exemplo, no próprio enredo do seriado, que aponta a traição do marido como a causa para a condição de "descasada" da protagonista da série.

Esse nosso gesto de análise decorre das condições de produção desse discurso, que traz consigo as condições sócio-históricas da mulher na sociedade brasileira, naquele momento. O divórcio havia sido instituído oficialmente no país há menos de um ano, por emenda constitucional em junho de 1977, e regulamentado pela Lei 6.515, de 26 de dezembro do mesmo ano. A mulher divorciada chega às telas da TV e à capa da revista Veja como uma nova categoria, a de "mulher descasada", que comparece na formação social porque está autorizada legalmente a pôr um fim ao seu casamento. Constituem-se, desse modo, efeitos de sentidos de necessidade para que a mulher decida sair do relacionamento ao lado de um homem e empreender uma nova jornada.

5 O filme norte-americano dirigido e produzido por Paul Mazurkis, em 1978, tem como título original "An Unmarried Woman". É interessante observamos, no entanto, os deslizamentos de sentidos que se produzem em versões do título nos diferentes idiomas para os quais foi traduzido, como em "Uma mulher só" (Portugal); "La femme libre" (França) e "Una donna tutta sola" (Itália). Essas informações sobre o filme, bem como sua sinopse e ficha técnica, estão disponíveis no site "70 anos de cinema", disponível em: $<$ http:// www.70anosdecinema.pro.br/673-UMA_MULHER_DESCASADA_(1978)>. Acesso em 13 fev. 2014.

6 exprime sobretudo: 1) oposição, negação ou falta: desabrigo, desamor, desarmonia, desconfiança, descortês, desleal, desproporção, dessaboroso; 2) separação, afastamento: descascar, desembolsar, desenterrar, desmascarar; 3) aumento, reforço, intensidade: desafastar, desaliviar, desapartar, desferir, desinfeliz, desinquieto; (HOUAISS, 2009, verbete "des", negritos nossos.) 
A formação imaginária projetada no dizer da revista para a mulher divorciada também pode ser depreendida no título da reportagem nas páginas internas de Veja: "A viajante solitária". Os efeitos de sentidos que se constituem para esta nova categoria de mulher se estabelecem por oposição à vida em um casamento, ou seja, a dois. Mas, no dizer da revista, não viver a dois, que é a condição do matrimônio em nossa formação social que se pauta pela prática da monogamia, não é viver sozinha ou estar a sós; é estar "solitária", condição da mulher "descasada", expressa na reportagem de Veja. O termo 'solitária' se inscreve em uma rede parafrástica em que predominam os dizeres sobre a solidão, produzindo efeitos de sentidos de um estar sozinho que ocorre a despeito de uma escolha do sujeito e que, por isso, traz sofrimentos.

Aos efeitos de sentidos que se constituem nas páginas de Veja para a mulher divorciada soma-se a sua qualificação como "aquela que sofre". A ênfase ao sofrimento da mulher divorciada é materializada na publicação em um boxe composto por quatro colunas, que tem como título "Diário de uma mulher descasada", e que apresenta alguns motivos pelos quais uma mulher divorciada "sofre". É preciso considerar, no entanto, que não há outro boxe com as vantagens do divórcio. Tal silenciamento (ORLANDI, 2002a) produz como efeito de sentido a impossibilidade de felicidade da mulher divorciada, que nessa sua nova condição passa a ter uma experiência subjetiva repleta e somente de sofrimentos. Recortamos uma SD do interior do boxe. Leiamos:

SD1: [a mulher divorciada] Sofre porque, quando um homem se separa, sempre encontra uma mulher que o ajuda a escolher os móveis para sua casa. (Veja, 18/07/1979, grifos nossos).

Na SD1, consta, entre a série de desvantagens de se estar divorciada, uma das razões pelas quais a mulher divorciada "sofre": o homem encontra mais facilmente outra mulher, mesmo após o divórcio. Esta construção discursiva coloca-se em relação ao fato de que a mulher, supostamente, tem mais dificuldade em encontrar outro parceiro. Ao não dizer deste modo, o discurso de Veja aponta para outra produção de sentidos: o homem divorciado, ao consumir, já o faz com uma nova parceira. Não se diz, entretanto, que a mulher divorciada não teria a mesma situação, mas tais efeitos de sentidos reverberam nesse dizer, uma vez que, conforme Orlandi (2001), o não-dito também significa no discurso.

O sofrimento que caracteriza a experiência subjetiva da mulher divorciada do seriado é marcado também na reportagem em relação à imagem do telespectador e, ainda, em relação à imagem da própria atriz que interpretava Malu na época, Regina Duarte. Vejamos a SD2:

SD2: [...] a mesma Globo que construiu a Regina-Namoradinha procura agora esculpir a Regina-Descasada. "A Malu de hoje é melhor que eu”, diz Regina. "Está na minha frente".

Está na frente, também, segundo desconfiam seus próprios autores, da imensa maioria de espectadores, descasadas ou não, que a cada semana se sentam diante do aparelho de TV mais ou menos na esperança de quem se senta diante de um espelho. (Veja, 18/07/1979, grifos nossos)

Enquanto personagem de uma série televisiva, Malu é construída no discurso de Veja como a representação de uma mulher cujas experiências estão "à frente" daquelas da atriz, Regina Duarte, mas também em relação às experiências dos telespectadores, sinalizados 
no discurso da revista como mulheres por meio da expressão "descasadas ou não", que explica quem são "a imensa maioria dos espectadores" do seriado, para quem a televisão funcionaria imaginariamente como "um espelho". Ao dizer desse sujeito mulher telespectadora, podemos observar que a revista Veja também retoma um efeito de sentido que se constitui para a televisão, desde os seus primeiros anos de exibição no país: a imagem de que a televisão caminha à frente da realidade, e que, ao mesmo tempo, funciona como seu espelho. Dela-Silva (2008) comenta este efeito "espelho" sobre a televisão, e afirma:

A imagem da televisão como um "espelho mágico", o que pressupõe a propriedade do aparelho de TV pelo telespectador-consumidor, encaminha para o sentido da televisão como um objeto de desejo e realizador dos desejos de felicidade promovidos pelo discurso publicitário. Ter a televisão nas residências equivale, assim, a possuir uma outra visão do mundo e dos acontecimentos, uma imagem projetada pela tela, de forma mais completa e complexa que nas mídias disponíveis, capaz de promover rupturas nas noções de espaço e tempo, ao levar para a esfera privada o âmbito público. (DELA-SILVA, 2008, p. 189).

No caso específico do seriado, a televisão é significada no discurso da revista como aquela que exibe, tal qual um espelho, o dia a dia da imensa maioria das mulheres que acompanhavam a narrativa sobre Malu, espectadoras que, a exemplo da própria atriz que interpreta a personagem "descasada", não estariam tão à frente de seu tempo. A imagem da mulher divorciada retratada no discurso de Veja, servindo-se da personagem, é projetada como uma mulher a quem falta o casamento ("descasada"), "solitária" em sua jornada, e que "sofre" por isso, social e emocionalmente.

É justamente o sofrimento emocional que a revista privilegia em seu dizer sobre a mulher divorciada, quando, em seu gesto de leitura de seu próprio arquivo, retoma, em sua edição de setembro de 2013, a reportagem de 1979. Nessa retomada, a publicação reproduz no início da nova reportagem, em um boxe com uma coluna, a imagem da capa de 1979 e também um trecho da reportagem anterior. É desse trecho que recortamos as SDs 3 e 4, que passamos a analisar:

SD3: [...] numa noite de junho, por volta de 10 e meia da noite, Malu foi vista por milhões de testemunhas entrando na bonita casa de praia de um amigo, em Ubatuba. De dia, ela havia depilado pernas e axilas, lavado os cabelos, exercitado ao telefone um tom de voz insinuante de promessas e esperanças. De noite, dirigiu-se à cama de um amigo, fez alguns rodeios, deitou-se e, diante de uma platéia consternada e aflita, fracassou miseravelmente. Mas por pouco tempo. Antes de 11 da noite, enlaçada pelos braços, pela compreensão e pela competência do amigo, ela voltava à cama para uma nova batalha de carícias. (Veja, 18/07/1979, grifos nossos).

Na SD3, vemos uma construção discursiva em torno da sexualidade da mulher divorciada. Sem a presença do então marido, a mulher precisa se lançar à relação sexual com outros parceiros que não mais o habitual. Assim, vale compreender que, neste modo de se conceber as relações, o homem em questão é designado no discurso jornalístico de Veja como "amigo". Por outro lado, as exigências sobre o corpo da mulher, agora divorciada, permanecem: o ritual de embelezamento da personagem do seriado, detalhado na SD3, aponta, sobretudo, para a necessidade de manutenção dos efeitos de sentidos de beleza e de higiene. $\mathrm{O}$ efeito de sentido de sedução pode ser observado no fio do discurso quando 


\section{Conexão Letras}

o dizer da revista afirma que Malu havia "exercitado ao telefone um tom de voz insinuante de promessas e esperanças”. Tal enunciado, nos equívocos da língua, produz efeitos de indeterminação de sentidos: promessas e esperanças para quem? Para Malu? Para o amigo? Para as telespectadoras que acompanham a história?

Nesta SD, o discurso de Veja ressalta os percalços da protagonista em alcançar o orgasmo sexual. No movimento de produção de sentidos, em que ela "fracassa miseravelmente", pesa sobre a mulher um retorno: assim como fracassou no casamento, fracassa no ato sexual. A saída para o fracasso, ou seja, o orgasmo, ocorre graças à ajuda masculina, conforme pode ser depreendido no fio do discurso em: "enlaçada pelos braços, pela compreensão e pela competência do amigo". As razões do fracasso anterior não são explicadas, mas é explicitada a razão pelo sucesso nesta nova investida: é o homem - dotado de "compreensão" e "competência" - que comanda o bem sucedido orgasmo de Malu.

Na produção de efeitos de sentidos sobre Malu e sobre as relações sexuais da mulher divorciada, é interessante compreender como o telespectador é designado: "testemunhas" e "plateia". Neste momento, está novamente em questão, a nosso ver, uma imagem sobre a televisão em seu funcionamento. Nas análises sobre o acontecimento discursivo da televisão no Brasil, Dela-Silva (2008) aponta que a televisão, no funcionamento do discurso das revistas, é construída “[...] como responsável por levar aos lares os acontecimentos mais diversos [...]”, (p. 178). Ou seja, a mulher divorciada, enquanto uma nova realidade na formação social brasileira, passa a comparecer na televisão, uma vez que esta estaria em sintonia com a diversidade nos papéis sociais de uma dada formação social. É possível depreender, no entanto, que tal "alinhamento" ocorre a partir da produção de determinados efeitos de sentidos: a mulher é responsabilizada pelo "fracasso" no ato sexual, enquanto o homem é responsabilizado por fazê-la retomar a "batalha de carícias".

A projeção de uma imagem de Malu e do telespectador prossegue na SD4, também recortada do trecho que a revista reproduz em sua edição de 2013 da reportagem que circulou em suas páginas em 1979. Vejamos:

SD4: MOMENTO DE ÊXTASE: Ainda aflita, quem sabe roendo as unhas numa torcida surda ou numa condenação silenciosa, a grande platéia plantada diante dos aparelhos de TV viu então uma cena extraordinária: a mão de Malu, primeiro crispada, soltava-se e abria-se numa prova de que o orgasmo finalmente explodia no vídeo nacional. Não se sabe a extensão de insônia e euforia que este momento de prazer provocou dentro dos lares. (Veja, 18/07/1979, grifos nossos)

Na SD4, temos o dizer de Veja que relata o modo como o orgasmo de Malu é representado na televisão. É a mão, em seus gestos, aquilo que atua como revelação do prazer da personagem. Compreendemos "mão" enquanto o que compõe a materialidade do "corpo discursivo" (FERREIRA, 2011; LUNKES, 2014), o que nos afasta de uma perspectiva organicista e biológica. Ferreira (2011), ao propor tal designação da materialidade do corpo, permite que se considere o corpo enquanto "materialidade significante" (idem, p. 174). Além disso, segundo a autora, tal designação é produtiva à medida que acolhe suportes outros que serão representantes dos discursos, já que uma materialidade que se filie somente à linguística não tornaria possível a inclusão do corpo, por exemplo, enquanto objeto de estudo.

Para Ferreira (2011), a materialidade do corpo atua enquanto "lugar de observatório", que permite a "visualização do sujeito e da cultura que o constitui", sendo que isso não significa um efeito de totalidade nesse gesto de leitura de olhar o corpo. Nesse "corpo que olha e que se expõe ao olhar do outro", permanece o "inapreensível” (idem, p.177). 
No funcionamento do discurso de Veja, a mão atua enquanto aquilo que torna possível representar o prazer sexual feminino. O intenso prazer de Malu, exposto na sutileza de uma mão que se abre na tela da televisão, é construído no discurso da revista em relação à reação do telespectador. Nesta produção de efeitos de sentidos, a polissemia se produz ante o subtítulo "Momento de êxtase". Afinal, no fio do discurso há um batimento entre a tensão do telespectador perante a cena de orgasmo da personagem e a cena propriamente dita. Há, inclusive, um destaque justamente ao telespectador e à reação deste diante da cena que coloca em evidência o prazer da personagem, qualificada pela revista como "uma cena extraordinária". O dizer da revista também marca, no fio do discurso, as diferentes reações que a cena de prazer pode produzir junto ao público: "torcida surda" ou "condenação silenciosa". As diferentes reações colocam em questão os modos pelas quais uma dada formação social lida com a explicitação do prazer feminino: enquanto há quem torça pela concretização do prazer da protagonista, há também quem condene. Aponta, ainda, para as tensões em torno do feminino e do prazer, mas, sobretudo, para o prazer de uma mulher divorciada.

Retomando um dos nossos objetivos neste artigo, de refletir acerca do arquivo de Veja que tematiza a mulher divorciada, levando em conta o próprio gesto da publicação de leitura sobre esse seu arquivo, cabe-nos indagar: por que, ao tematizar a mulher divorciada, a revista retoma justamente esse trecho de sua reportagem anterior que diz sobre a sexualidade da mulher divorciada? Que efeitos de sentidos estão em jogo nesse seu gesto de leitura de seu próprio arquivo? Em busca de possíveis respostas, passemos à análise de duas SDs recortadas dessa segunda reportagem de Veja, presente em sua edição comemorativa de 45 anos, com o título: "Malu mulher de verdade":

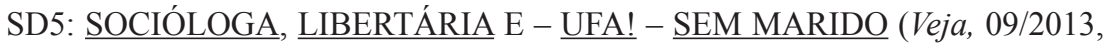 grifos nossos)}

SD6: Em reportagem de capa VEJA flagrou, no rastro da enorme audiência de Malu, uma nova realidade do país: o crescimento do número de mulheres descasadas. Foi um susto pela TV. (Veja, 09/2013, grifos nossos)

No gesto de leitura que faz de seu próprio arquivo, ao apresentar a capa de sua edição de 1979 e um pequeno trecho da reportagem anterior que, como vimos nas SDs 3 e 4, colocam em questão sentidos sobre a sexualidade da mulher divorciada, Veja qualifica a "mulher descasada" que retratou em sua matéria jornalística do final da década de 1970 como "socióloga", "libertária" e "sem marido", como podemos observar no fio discursivo da SD5. O termo "socióloga" retoma a profissão da personagem Malu no seriado e, associada à "libertária", aponta para outros efeitos de sentidos sobre a mulher divorciada, afirmando a sua qualificação profissional e o seu suposto desejo por liberdade, que a levaria, como marcado na exclamação "Ufa!", a ficar "sem marido", ou seja, à condição de "descasada", já exposta na reportagem de 1979 .

No relato que faz de sua reportagem anterior, na SD6, destacamos a forma verbal "flagrou" com que Veja, via discurso relatado (AUTHIER-REVUZ, 1990), introduz o seu dizer sobre a constatação do "crescimento do número de mulheres descasadas", também qualificado como "um susto". "Flagrar" encaminha para sentidos de descoberta de uma situação improvável e/ou inesperada, ao menos da posição ideológica ocupada por Veja e, supostamente, por seus leitores. A formação imaginária da mulher descasada construída 


\section{Conexão Letras}

no discurso de Veja e que é retomada em suas páginas atuais, inicialmente, é a daquela que causou surpresa e espanto ao passar a viver "sem marido". Cabe destacar que a expressão "sem marido" com que Veja retoma a sua reportagem sobre "a mulher descasada" marca explicitamente algo que falta a mulher na condição de divorciada: um marido, mantendo-se, assim, em relação de paráfrase com o discurso da revista em sua reportagem anterior.

Da reportagem de 2013, que, como dissemos, é redigida por uma historiadora a convite de Veja, destacamos as três últimas SDs que trazemos para análise, de modo a pensar na formação imaginária que se constitui na atualidade para "a mulher descasada":

SD7: Malu mudou. E o Brasil também. Pesquisas recentes demonstram que pessoas

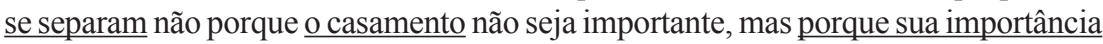
é tão grande que os cônjuges não aceitam que ele não corresponda às expectativas. (Veja, 09/2013, grifos nossos)

SD8: Mas as mulheres continuam - ai delas - românticas: hoje, com ou sem marido, com ou sem família, um único assunto as ocupa, o amor. Diferentemente de Malu, ávida por emancipação, as jovens de nosso tempo aprendem por meio de maciça doutrinação - via cinema, novelas, músicas, jornais e anúncios publicitários - que o amor é a chave que abre as portas do paraíso na terra. (Veja, 09/2013, grifos nossos)

SD9: O problema não está mais em ser descasada como a Malu de Regina Duarte,

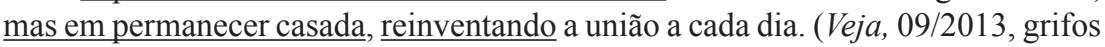
nossos)

No fio discursivo das SDs 7 e 8, uma marca se destaca de imediato: a oposição que é estabelecida entre a Malu, que representa a "mulher descasada" retratada na reportagem de 1979, o Brasil e "as mulheres" de um modo geral. Enquanto na SD7 temos a afirmação de que "Malu mudou. E o Brasil também", "as mulheres" são associadas na SD8 à permanência, à constância, uma vez que elas, diferentemente de "Malu" e do "Brasil", continuariam "românticas". A mulher descasada agora é substituída por "pessoas" que "se separam", como marcado na SD7, e que supostamente agora o fazem em decorrência de suas altas expectativas a respeito do casamento e do que essa experiência de vida a dois deveria proporcionar.

Nas SDs 7 e 8, está em questão um movimento nos processos de adjetivação da mulher no discurso de Veja: de "descasada" para "separada". Tal processo, no entanto, não implica em uma mudança da imagem construída sobre a mulher, nesses mais de 30 anos que separam as duas reportagens. $\mathrm{O}$ romantismo, o anseio urgente pelo amor - marcado no discurso da revista como o "único" assunto pelo qual as mulheres se interessariam na contemporaneidade - não somente retoma a imagem de uma mulher interessada na relação amorosa, e, talvez, na instituição do casamento, mas reforça a imagem de que se trata, afinal, da verdadeira ocupação feminina, o que mantém o conservadorismo das relações em nossa formação social. Se, na matéria de 1979, o desejo de Malu, segundo o discurso da revista, era o de "se emancipar", na matéria de 2013, segundo o discurso de Veja, a mulher, emancipada e conquistando cada vez mais o mercado de trabalho, deseja ter amor, o que constitui a imagem de uma mulher que precisa do outro, precisa de uma relação amorosa, como também precisava Malu.

Há um movimento nas relações de sentidos entre amor e casamento na trama do discurso de Veja, o que confere ao casamento, de certo modo, o status de um lugar no qual a mulher busca o amor; por outro lado, o amor é uma das respostas diante da escolha da 
mulher de casar-se. Neste movimento de sentidos, a maior dificuldade não está mais em se separar, mas em se manter em um casamento, significado como uma condição feminina. O verbo "reinventando", que marca o fio do discurso da SD9, aponta para as dificuldades da mulher na contemporaneidade e para a cristalização dessa imagem de mulher que quer/ precisa se manter no amor/no casamento.

Nessa sobreposição de sentidos que os dizeres em circulação em Veja promovem entre amor e casamento, atualiza-se uma tensão em relação às demandas da mulher: se em 1979 a dificuldade estava, sobretudo, na aceitação de sua condição de divorciada pela formação social, em 2013, mesmo com a aceitação social de tal condição, é a mulher quem quer/ precisa de amor, ou seja, não aceita viver sem este afeto, pressuposto no discurso de Veja pelo termo "união". A imagem da mulher constitui-se, assim, na alternância entre o desejo de aceitação social e a busca pelo amor do outro, o que não deixa, igualmente, de implicar a aceitação social.

No trajeto temático que depreendemos em Veja, observamos que a mulher - "descasada", "solitária", "sofredora" e "fracassada" - projetada no discurso de Veja quando da institucionalização do divórcio no Brasil é ressignificada como aquela que, na atualidade, por oposição à "libertária" Malu da TV - que, por sinal, estava muito "a frente de seu tempo" -, "continua romântica", em busca do "amor" e do desafio de "reinventar a união a cada dia"; uma ressignificação que, mesmo por outras vias, reinscreve o dizer da revista em um já-dito sobre a imagem da mulher que a associa à emoção e à fragilidade. Conforme afirma Magalhães (2011, p. 24), em suas análises a respeito das representações do feminino em obras literárias, "a discriminação que a mulher sofre na sociedade moderna inculca-lhe a visão do social de fragilidade e inoperância", sentidos que, a nosso ver, caminham ao lado do trajeto temático sobre a mulher divorciada, depreendido do dizer de Veja.

No gesto de leitura que empreende de seu próprio arquivo na atualidade, entendemos que Veja, em sua edição comemorativa, constitui uma memória de arquivo (ORLANDI, 2006; 2002) para a mulher divorciada, ao dizer o que se pode e se deve lembrar sobre essa mulher, desde que o divórcio tornou-se uma possibilidade no país. Quando pensamos esse gesto discursivamente, interessa-nos especialmente o modo como, ao constituir uma memória de arquivo, a revista inscreve o seu dizer em uma memória discursiva, atualizando certos efeitos de sentidos sobre a mulher, ao mesmo tempo em que impede que outros compareçam. É no movimento dos sentidos - de "descasada" a "romântica" - que a materialidade dos dizeres de Veja se inscreve na história e revela o seu funcionamento discursivo. Um funcionamento que a simples chancela de arquivo de Veja não nos dá a conhecer, mas que a noção de arquivo na análise de discurso permite-nos compreender.

\section{Referências}

AUTHIER-REVUZ, Jacqueline. Heterogeneidade(s) enunciativa(s). Trad. Celene Cruz e João W. Geraldi. Caderno de Estudos Linguísticos, Campinas, SP, n.19, jul./dez. 1990, p. 25-42.

DELA-SILVA, S. (Re)significando a TV: apontamentos sobre a memória no discurso midiático. In: SCHERER, A.; ROMÃO, L.M.S; MEDEIROS, V.; PETRI, V. (Orgs.). Lingua, sujeito e memória: um enlace pelo discurso. No prelo.

. O acontecimento discursivo da televisão no Brasil: a imprensa na constituição $\overline{\text { da TV }}$ como grande mídia. 2008. Tese (Doutorado em Linguística). Instituto de Estudos da Linguagem, Unicamp. Campinas, SP, 2008. 


\section{Conexão Letras}

DICIONÁRIO DA TV GLOBO, vol. 1: programas de dramaturgia \& entretenimento. Projeto Memória das Organizações Globo. Rio de Janeiro: Jorge Zahar Editor, 2003. FERREIRA, M.C.L. Discurso, arquivo e corpo. In: MARIANI, B.; MEDEIROS, V.; DELA SILVA, S. (Orgs.). Discurso, arquivo e... Rio de Janeiro: 7Letras, 2011, p. 174-183. GUILHAMOU, J.; MALDIDIER, D. Efeitos do arquivo. A análise do discurso no lado da história. In: ORLANDI, E.P. (Org.). Gestos de leitura: da história no discurso, 3 ed. Campinas-SP: Editora da Unicamp, 2010. p. 161-183.

HOUAISS, A. Dicionário Eletrônico Houaiss da Língua Portuguesa. São Paulo: Objetiva, 2009.

JAKOBSON, R. [1960]. Lingüística e Poética. In: Lingüística e Comunicação. Trad. Isidoro Blikstein e José Paulo Paes. 22 ed. São Paulo: Cultrix, 2010. p.150-207.

LUNKES, F.L. O discurso sobre depressão na revista Veja em materialidades verbais e não-verbais: o triunfo dos efeitos de sentidos de medicalização. 2014. Tese (Doutorado em Estudos de Linguagem). Instituto de Letras, Universidade Federal Fluminense. Niterói, RJ, 2014.

MAGALHÃES, B. Contradição social e representação do feminino. Maceió-AL: EDUFAL, 2011.

MARIANI, B. O PCB e a imprensa: os comunistas no imaginário dos jornais (19221989). Rio de Janeiro: Revan; Campinas-SP: Editora da Unicamp, 1998.

NUNES, J.H. O discurso documental na História das Idéias Lingüísticas e o caso dos dicionários. Alfa, São Paulo, n. 52 (1), p. 81-100, 2008.

. Formação do leitor brasileiro: imaginário da leitura no Brasil. Campinas-SP:

Editora da Unicamp, 1994.

ORLANDI, E.P. Análise de Discurso. In: LAGAZZI RODRIGUES, S.; ORLANDI, E.P. (Orgs.). Introdução às ciências da linguagem. Discurso e textualidade. Campinas-SP: Pontes, 2006. p. 11-31.

. Lingua e conhecimento linguístico: para uma história das ideias no Brasil. São

Paulo: Cortez, 2002.

. As formas do silêncio: no movimento dos sentidos. 5 ed. Campinas-SP: Editora

da Unicamp, 2002a.

. Análise de discurso. Princípios e procedimentos. 3 ed., Campinas: Pontes, 2001.

PÊCHEUX, M. [1981]. Ler o arquivo hoje. In: ORLANDI, E.P. (Org.). Gestos de leitura: da história no discurso, 3 ed. Campinas-SP: Editora da Unicamp, 2010. p. 49-59. . [1969]. Análise automática do discurso (AAD-69). Em Por uma análise automática do discurso, organizado por Françoise Gadet e Tom Hak, 3 ed. Campinas: Editora da Unicamp, 1997. p. 61-161.

. [1975]. Semântica e discurso: uma crítica à afirmação do óbvio. 3 ed. Campi-

nas: Editora da Unicamp, 1997a.

ROMÃO, L.M.S. Exposições do Museu da Língua Portuguesa: arquivo e acontecimento e(m) discurso. São Carlos: Pedro \& João Editores, 2011.

ROMÃO, L.M.S.; LEANDRO-FERREIRA, M.C.; DELA-SILVA, S. Arquivo. In: MARIANI, B.; MEDEIROS, V.; DELA-SILVA, S. (Orgs.). Discurso, arquivo e.... Rio de Janeiro: 7 Letras/FAPERJ, 2011. p. 11-21.

VEJA: Edição Especial 45 anos. São Paulo: Ed. Abril, n. 2.340, set. de 2013. 290 p.

VEJA. São Paulo: Ed. Abril, n. 567, 18 jul. 1979. 